\title{
Interpretaciones recientes de la Revolución mexicana*
}

Alan Knight

In esta ponencia quiero poner en perspectiva los trabajos recientes sobre la Revolución mexicana, prestando especial atención a la gran cantidad de interpretaciones revisionistas ${ }^{1}$ que han aparecido en estos últimos veinte años.

La historiografia revolucionaria se puede dividir de muchas formas: pero un modo, a mi parecer, es por generaciones, más o menos como explico a continuación. Una primera generación de escritores estaria compuesta por los participantes/observadores comprometidos; incluiría escritores/intelectuales mexicanos, tanto de la izquierda (Silva Herzog, Fabela, Molina Enriquez), como de la derecha (Bulnes, Vera Estañol), asi como influyentes comentaristas extranjeros, como Tannenbaum y Gruening (Tannenbaum, especialmente, es la bête noire de los revisionistas). También incluiria a muchos de los mismos participantes revolucionarios que escribieron sus memorias, diarios y apologias (Salvador Alvarado o Gabriel Gavira serian buenos ejemplos). Aunque a menudo son muy partidistas y a veces algo pesados (tomamos como ilustración el celebre Ocho mil kilómetros en campaña de Alvaro Obregón que, cuando se lee, parecen mínimamente ochocientos mil). Sin embargo, los de la primera generación forjaron una imagen de la Revolución -popular, campesina, agraria, nacionalista- que fue coetánea de la Revolución misma. Estaban, por supuesto, comprometidos; pero justamente por ello pescaron algo del sabor intangible de la experiencia revolucionaria (un aspecto al que volveré más tarde).

Echaron además las bases para una segunda generación de historiadores académicos que publicaron principalmente en los cincuenta y los sesenta, concentrándose normalmente en las elites nacionales, prefiriendo un enfoque narrativo, y reemplazando el partidarismo abierto por la objetividad académica. Así, en los Estados Unidos tenemos entre otros a Ross, Cumberland y Quirk; en México a Valadés, Ulloa, Blanco Moheno, y el destacado equipo que. bajo la coordinación de Cosío Villegas, preparó la Historia moderna de México. Si bien su giro académico, "objetivo" y narrativo, los apartó de las generalizaciones grandiosas (raras veces ofre-

- Ponencia presentada en el Simposio de Historiografía Mexicanista en Oaxtepec, Morelos, 1988. A la versión original se agreggan dos apartados de aclaración.

'Vale aclarar que el término "revisionismo" tiene un sentido neutral y se refiere a las nuevas corrientes de interpretación histórica que, de las maneras que yo menciono, han avanzado en contraposición a la vieja ortodoxia. No tiene nada que ver con el "revisionismo" marxista. Además, no quiero decir que todas las historias recientes sean revisionistas: muchas no tienen un enfoque interpretativo, claro, otras son más bien "tradicionales" $u$ ortodoxas. Pero con todo, creo que la interpretación general de la Revolución que se ha impuesto en los últimos años muestra claros rasgos "revisionistas". 
cieron interpretaciones globales de la Revolución) sí tendieron a permanecer dentro del paradigma expuesto por Tannenbaum, que podríamos llamar la vieja ortodoxia. Esta se basa en el concepto de una revolución popular, agraria, espontánea, caracterizada por una sólida participación campesina y una confrontación en gran escala de campesinos y terratenientes (a veces "latifundistas feudales"), así como por sentimientos intensos de nacionalismo, incluso xenofobia. Tal imagen de la Revolución implicaba ciertas consecuencias para la interpretación del Porfiriato, como un régimen de opresión, autoritario y extranjerizante. Según la vieja ortodoxia, la Revolución -una auténtica revolución social, con fuerte contenido de clase- derrocó al régimen porfirista y produjo un régimen nuevo, más radical, nacionalista y reformista que, a pesar de interrupciones, regresiones y traiciones, representó un cambio sustancial con respecto al Porfiriato; por eso mereció la etiqueta de "revolución social" (algo raro en la historia del mundo). Aun cuando esta segunda generación se concentró, como lo hizo a menudo, en los grandes hombres y en los grandes hechos, las suposiciones fundamentales todavia eran las de la vieja ortodoxia.

Aproximadamente en los últimos veinte años una tercera generación ha madurado. Son los baby-boomers de la historiografía mexicana. Son más numerosos, quizás más profesionales; tienen una visión más cercana y concentrada; pero, en consecuencia, a veces sufren de miopía. De acuerdo con las tendencias historiográficas globales, se especializan por tema, hasta por metodología. Han saqueado los archivos como nunca jamás (coincidentemente, los archivos mexicanos aumentaron y mejoraron en organización). $\mathrm{Y}$, a diferencia de sus predecesores, a quienes a veces desprecian, han tratado de evitar la previa concentración en las elites y los lideres y de ver la historia desde abajo; es hora de que los de abajo reciban su merecida atención (irónicamente, estos mismos historiadores a veces concluyeron que los de abajo no eran sino pura carne de cañón).

La característica más notable de esta generación es su cantidad y el volumen de su producción. Como observó David Bailey hace diez años: "hasta los especialistas se encuentran agobiados al tener que leer -y a veces localizar- los libros, artículos y disertaciones que aparecen en abundancia no sólo en México y los Estados Unidos, sino también en otra media docena de países". (Esto me sirve de excusa previa por todo lo que no menciono aquí.) Tal volumen de producción refleja en primer lugar el crecimiento de la enseñanza superior en los distintos países; en segundo lugar, el hecho de que las cosas latinoamericanas, especialmente las revoluciones, estaban de moda en los años sesenta; y en tercer lugar el inevitable ciclo historiográfico, según el cual, con el pasar del tiempo y el acceso a los archivos, temas que en un momento fueron "de actualidad", retroceden en el tiempo, escapan de las garras irresponsables de periódistas, y encuentran refugio entre los historiadores serios como nosotros.

El correr del tiempo, sin embargo, tuvo otras consecuencias. En primer lugar, los historiadores se distanciaron de su tema; si bien ello contribuyó a una mayor objetividad, no fomentó necesariamente mayor entendimiento o empatía (verstehen, en el sentido weberiano clásico). A veces, sobre todo en los Estados Unidos, el 
sentido de empatia con el contexto -por los sentimientos intangibles de los actores históricos- dio paso a una veneración más positivista de "los hechos", especialmente de los hechos concretos ( hard facts), y, de ser posible, de los hechos cuantitativos. Además, a partir de 1968 , se inició un periodo en que el sistema político mexicano y el milagro económico parecieron vacilar (desde la perspectiva actual nos podríamos preguntar a qué se debia tanta hazaña). Pero no debe sorprendernos que aquellos historiadores que habian conocido de primera mano la paz del PRI, el llamado milagro, Tlatelolco y las rituales invocaciones oficiales de la Revolución, que tantas veces contradecían la realidad mexicana, llegaran a preguntarse cuál era la realidad de la Revolución y sintieran un deseo de desenmascarar y de desmitificar la Revolución deificada.

Desde fines de los sesenta, nuevas y detalladas monografias -libros, tesis, articulos- inundaron el mercado. Dada su cantidad absoluta, es obvio que no seguian -que no podian seguir- un patrón común. Algunos historiadores probaban nuevas metodologias: la historia cuantitativa (Coatsworth, Wilkie, Smith, Guerra); la historia oral (Arturo Warman y Eugenia Meyer, y sus equipos respectivos, que apuntaron memorias populares desvanecientes, dejándonos el valioso Archivo de la Palabra); o James Wilkie, otra vez, que grabó los recuerdos más estudiados de los políticos de la elite. Generalmente, empero, la historia oral era una forma de llegar a la historia "desde abajo", y reflejaba una tendencia global, de ninguna manera limitada a México.

Pero el enfoque más común para esta historia fue el regional o local (voy a juntar estas categorías). Es decir que, aparte de su originalidad de archivo o de su postura critica frente a la revolución oficial, la nueva historia de los "post sesenta" se caracterizó ante todo por su enfoque local o regional. Tal enfoque, por supuesto, no era nuevo; existia una tradición venerable de historias de la patria chica, algunas muy útiles; pero ahora los historiadores "profesionales", mexicanos y extranjeros, adquirieron sus propias patrias chicas adoptivas (y a veces sus propios chauvinismos locales para acompañarlas). La lista es larga, y no puedo dejar de mencionar algunos que yo conozco: Aboites (Yucatán), Aguilar Camín (Sonora), Ankerson (San Luis), Benjamin (Chiapas), Buve (Tlaxcala), Falcón (Veracruz y San Luis), Fowler (Veracruz), Jacobs (Guerrero), Joseph y Wells (Yucatán), Martínez Assad (Tabasco), Jean Meyer (principalmente Michoacán y Jalisco), Paoli y Montalvo (Yucatán), Ruiz Cervantes (Oaxaca), Schryer (Hidalgo); y las contribuciones a simposios importantes como el Caudillo y campesino, editado por Brading; Other Mexicos, de Benjamin y McNellie; La Revolución en Oaxaca, de Martínez Vázquez; y La Revolución en las regiones de Martínez Assad. Por supuesto, el gran pionero y decano de la historia local -de la microhistoria- es Luis González; y hay varios centros florecientes en México que generan valiosos estudios locales, por ejemplo el Instituto Mora, el Centro de Estudios de la Revolución Mexicana de Jiquilpan, el Colegio de Michoacán, el Colegio de Jalisco, y otros más.

El rasgo más obvio e indiscutible de la historiografia revolucionaria posterior a los sesenta ha sido su desagregación geografica 0 espacial. El historiador nacional -la norma en el periodo anterior- 
ha sido remplazado por el historiador regional y local. Y no hay duda que esto representa el progreso evolutivo. Por supuesto, hay esfuerzos opuestos, que buscan la agregación: los estudios sintéticos, ya sean nacionales y totalizantes en sus enfoques o, por lo menos, nacionales en su tratamiento de temas específicos. Los estudiosos de las relaciones exteriores de la Revolución son un grupo, que omito (forman un grupo separado, si bien vale la pena anotar que el estudio más destacado de relaciones exteriores -la Guerra secreta de Friedrich Katz - también arroja mucha luz sobre la política doméstica y los movimientos sociales).

Dada la plétora de monografías recientes y la mayor abundancia de archivos, ha sido difícil sintetizar temas estrictamente domésticos, como el trabajo o el campesinado. Tenemos algunos buenos estudios del trabajo (Carr, Ruiz, Hart, Anderson), además de la valiosa serie coordinada por Pablo González Casanova, La clase obrera en la historia de México. Pero todos éstos tienden a concentrarse en las industrias principales (como las textiles) y en las confederaciones nacionales (CROM, CTM). La historia laboral mexicana todavía está un poco atrasada con respecto a sus equivalentes europeos y norteamericanos - no a los latinoamericanos- en cuanto se trata de romper la tiranía de las siglas y de buscar la reconstrucción de las vidas reales del trabajo, es decir, de la formación de la clase laboral mexicana (the making of the Mexican working class). Pero tenemos ejemplos pioneros entre las ponencias de la Quinta Reunión de Historiadores Mexicanos y Norteamericanos (como la de Lief Adleson), además del libro breve pero bueno de Garcia Diaz sobre Santa Rosa.

El sector agrario -hacienda, campesino, ranchero- ha recibido mayor atención, en parte por medio de los trabajos regionales y locales mencionados, asi como por una serie de valiosos trabajos sobre la hacienda (Marijosé Amerlinck de Bontempo, Jan Bazant, Marco Bellingeri, Juan Felipe Leal, Herbert Nickel, Manuel Plana, Beatriz Rojas, María Vargas Lobsinger); y recientemente han aparecido sintesis más ambiciosas: de Tutino, Katz y Coatsworth. Jean Meyer y Francois-Xavier Guerra han corregido algunos errores estadísticos, mientras que Brading, Jacobs, Falcón y Schryer han rescatado al pobre ranchero del olvido (creo que ya podemos dejar de lamentar su descuido historiográfico). Pero si bien sabemos bastante más sobre el cambio agrario en el México central y norteño, el México sur permanece como una especie de tierra incógnita agraria, especialmente fuera de Yucatán.

Entretanto, nuestro conocimiento de la educación ha aumentado enormemente con el trabajo de Josefina Vázquez, Victoria Lerner, David Raby, John Britton, y Mary Kay Vaughan. Alicia Hernández -entre otras cosas- ha llevado la investigación de los militares revolucionarios mucho más allá de donde lo dejaron Ed Lieuwen y Hans-Werner Tobler. Las biografias de Falcón (Tejeda), Hall (Obregón), Meyer (Huerta, Orozco), Richmond (Carranza), Zevada (Calles), y, por supuesto, Enrique Krauze (todo el mundo) han arrojado luz sobre la alta política de la época. Y esperamos ansiosamente el libro del profesor Katz sobre Villa, que complementará el estudio clásico de Womack sobre Zapata. El reciente simposio de Martinez Assad, Estadisticas, caciques y caudillos, muestra una combinación útil de la biografía y la historia 
local. Es de hacer notar que, con la excepción parcial de Krauze, ningún biógrafo ha sometido a su personaje al análisis psicohistórico. Para bien o para mal, el hombre de a caballo rara vez desmonta para acostarse en el sofá del analista, y es exagerado decir que la investigación del conflicto entre la Iglesia y el Estado ha sido revolucionado por el trabajo sobresaliente de Jean Meyer (hábilmente apoyado por otros especialistas como Alicia Olivera y David Bailey). Este, en realidad, es un tema que se traspasa con mayor facilidad a la historia nacional; como voy a sugerir, la fuerza del estudio revisionista de Meyer sobre la Cristiada (un movimiento que, a pesar de su importancia, fue limitado en el tiempo y en el espacio) le ha permitido ejercer -como un planeta gigante- una influencia gravitacional profunda, que sobrepasa su propia órbita.

Esto nos trae a lo esencial: las interpretaciones de la Revolución estimuladas por los trabajos recientes. Primero, hay que subrayar que la conversión de trabajos locales en síntesis generales no es una tarea fácil. Ante estos trabajos, el historiador tiene varias opciones. Una es evitar totalmente cualquier sintesis, y ver la Revolución como un mosaico irreductiblemente complejo, carente de forma, desafiante de toda generalización (volveré a éste, el enfoque "mosaico"). Una segunda opción es la de la comparación restringida, digamos ad hoc, que pueda producir observaciones útiles -hipótesis de mediano rango, por ejemplo contrastes entre regiones- pero no auténticas sintesis estructuradas. Una tercera opción consiste en generalizar un caso particular ya afirmando osadamente, ya sugiriendo tácitamente su tipismo para todo o casi todo México. Me parece que esto es lo que a veces hace Jean Meyer, si bien lo hace con gran fuerza y brio: es decir, en la experiencia centroccidental de la Cristiada subyace su interpretación cabal del Estado callista y, por extensión, de la Revolución mexicana en su totalidad. Por supuesto este proceso de generalización tácita y cada vez más amplia no quiere decir que Meyer descuide contrastes y afirme escuetamente el tipismo neto de la Cristiada (es demasiado buen historiador para hacer eso); pero el efecto es suficientemente marcado como para llamar a la Revolución de Meyer una revolución vista a través del vidrio de color cristero $\mathrm{y}$, por tanto. fuertemente matizada.

Una cuarta opción, última y contrastante, consiste en negar el tipismo de cualquier caso, en afirmar no su tipismo sino su peculiaridad; y asi, implicitamente, generalizar (negativamente) sobre el resto de la Revolución. El ejemplo más claro y común de esto es el zapatismo, el que a menudo se plantea como el único movimiento revolucionario agrario campesino auténtico dentro del caos y del caudillismo de la revolución armada (por ejemplo, Ruiz, al que volveré).

Asi, a medida que los historiadores comienzan a asimilar este montón de nuevos trabajos, también -implícita o explícitamentegeneran interpretaciones más globales de la Revolución. Algunos han ido hasta el limite, ensayando sintesis auténticas: Jean Meyer, Francois-Xavier Guerra, Ramón Ruiz, Hans-Werner Tobler, John Hart y yo. También la Historia de la Revolución Mexicana publicada por el Colegio de México representa una excelente sintesis; 
pero, siendo de varios autores, es dificil sacar de ella una interpretación cabal. Es interesante notar que los sintetizadores son todos extranjeros, la mayoria europeos. Esto no es, yo creo, puramente fortuito. Tampoco es prueba de la superioridad europea. Los europeos tienen menos acceso a las fuentes primarias; por lo tanto se inclinan hacia la síntesis; también actúan en un ambiente académico en el que la historia de México es un reino lejano y exótico, y de ahí que se empeñen en enseñar y escribir en un nivel más alto de generalización sólo por justificar su existencia (hablo de mi propia experiencia). De otra parte, se sienten menos inhibidos por la proximidad de especialistas rivales (como se sienten a veces los mexicanistas norteamericanos: hablo de mi propia experiencia más reciente). Mientras que para el mexicanista norteamericano (y yo supondria, mexicano) la neurosis profesional puede ser la claustrofobia, el temor a rivales cercanos, la neurosis del mexicanista europeo se parece a la agorafobia: es decir, sufre la sensación de recorrer un terreno vasto y vacio, encontrándose a veces con un colega, como Stanley se encontró con Livingstone en el Congo, con quien es más sensato comer pan que pelear.

Los sintetizadores, entonces, son pocos y muchas veces extranjeros. Pero, como he sugerido, las interpretaciones generales se forman poco a poco como arrecifes de coral, al mismo tiempo que se construyen arquitectónicamente, como rascacielos. Por lo tanto dependen bastante de trabajos que no son sintéticos, y de historiadores que no son historiadores nacionales. Por ejemplo, mencionaría los muy buenos y diversos trabajos de Romana Falcón que han influido bastante en la perspectiva revisionista. Otros historiadores regionales también hacen sus contribuciones de las maneras mencionadas. Todo se acumula. ¿Cuál es el resultado? Yo elegiría cuatro amplias áreas de las cuales uno puede sacar conclusiones interpretativas, en particular las revisionistas. La primera trata de la homogeneidad o heterogeneidad de la Revolución, una cuestión que debe preceder cualquier intento de mayor generalización. La segunda trata del carácter de la revolución armada misma. La tercera y cuarta -estrechamente relacionadas- tratan del Porfiriato y del régimen posrevolucionario.

La acumulación de investigación reciente ha mostrado claramente la complejidad de la Revolución. "Los muchos Méxicos", "los otros Méxicos", son las frases de moda. Y con razón. Pero esta es una ganancia modesta. La supuesta ortodoxia -la de una revolución popular, monolítica, homogénea- es un mito total $(0$, si prefieren, un hombre de paja gigante). Hoy, sus solos protagonistas son ideólogos oficiales, y creo que no vale la pena pelear con ellos. Tannenbaum, el abanderado ortodoxo, se expresó muy claramente en este sentido, como debió hacerlo, dado su conocimiento intimo del México revolucionario. En efecto, la heterogeneidad de la Revolución era una pieza clave en su argumento. La Revolución, escribió, "no ha sido una revolución nacional en el sentido de que todo el país participó en el mismo movimiento y al mismo tiempo. Ha sido local, regional, hasta por municipios". Según Tannenbaum, entonces, la Revolución no fue monolítica; y tampoco fue unidireccional. "Tan rápidas y variadas han sido las corrientes que han venido a la superficie en la Revolución que es 
muy difícil descubrir alguna dirección en el movimiento". 2

Por lo tanto, decir que la Revolución no fue monolítica, que había "muchas revoluciones", no es decir nada profundo ni original. Por cierto, no es una refutación de Tannenbaum. A lo más, es un exorcismo ritual de la ideología oficial, de la Revolución mitificada; en términos académicos es un buen comienzo, pero una conclusión banal. La pregunta clave es ¿a dónde se va de ahi? Por supuesto, podemos parar alli, quedándonos contentos con la revolución mosaico: tantas "revoluciones como hay regiones, movimientos, individuos". La Revolución se hace un collage desconcertante de sucesos y peculiaridades atómicos. La historia oral, si se hace con anteojeras, puede llevarnos en esa dirección. Las memorias de individuos (especialmente si se les quitan los raciocinios posteriores) sugieren a veces un conjunto fortuito de motivos personales (el deseo de "ir a la bola" o de escapar de una suegra insoportable), motivos difíciles de generalizar. Los relatos orales de la Revolución son, similarmente, episódicos y aparentemente carentes de sentido. ${ }^{3}$ También las imágenes de la Revolución procedentes de fuentes literarias -hasta del incomparable Azuela- tienden a ser caóticas y sin pauta. Las masas son carne de cañón ignorantes, los lideres cínicos, contendientes por el poder, y la Revolución misma es una metáfora de un dios inexorable y arbitrario. Es interesante notar que esta visión de una revolución sin razón y sin meta también emerge intensamente de las fuentes diplomáticas extranjeras, así como de algunos relatos orales y literarios. En suma, no falta el parque con qué apuntar a la imagen de una revolución social, popular, legítima.

Pero seguir este camino -abrazar el azar y el individuo y negar toda forma o patrón al proceso revolucionario- es, a mi parecer, un consejo de desesperación, aun si se puede justificar con una especie de sofisticación académica (es decir, hablando en términos despectivos, de teorías metahistóricas o de lechos de Procusto: los sofismas consabidos de un empirismo quisquilloso). Aquí, ayuda establecer un paralelo con la historiografia de la Revolución francesa. Una escuela ha proseguido asiduamente cada vez más investigaciones sobre cada vez menos, dedicando muchas páginas a los incidentes espeluznantes del Terror Blanco en Lyon, o a la ola de suicidios de camareras embarazadas en París. La historiografia de la Revolución mexicana no ha llegado tan lejos (el volumen de producción es menor y los archivos, sobre todo los policiacos, no son tan abundantes o informativos). Sin embargo, la muerte de la Revolución francesa a través de mil cuchilladas empiricas nos da una lección sensata para nosotros los que estudiamos la Revolución mexicana. El trabajo de archivo en sí no aporta conocimiento histórico. Más investigaciones y publicaciones no quiere decir necesariamente mejorar; la historiografia no progresa inevitablemente de una generación a otra. Algunos de los revisionistas de hoy, duros y osados criticos de Tannenbaum o Molina Enriquez, me ha-

\footnotetext{
${ }^{2}$ Frank Tannenbaum, Peace by Revolution: Mexico after 1910, Nueva York, Columbia University Press, 1966, p. 121 y 147.

${ }^{3}$ Véase la interesante discusión de Arturo Warman,... Y venimos a contradecir. Los campesinos de Morelos y el Estado nacional, México, Ediciones de la Casa Chata, 1976, p. 104- 105.
} 
cen pensar en esos individuos que graban sus iniciales en los cadáveres de ballenas varadas en la playa, bien muertas. $Y$-aunque esto es un asunto de preferencia personal- creo que no se puede establecer la realidad de la Revolución simplemente narrando experiencias individuales y relatos minuciosos. Hay patrones históricos que los mismos sujetos históricos desconocen; 0 , razonando de otra forma, los historiadores, tanto como los economistas, sociólogos, o psicólogos, deben incorporar en su análisis motivos y funciones, no sólo manifiestos sino también latentes. Los cristeros se alzaron para defender su fe, según nos dicen ellos mismos; pero eso no acaba con la lista de factores explicativos que están en la base de la Cristiada. Algunos villistas decidieron ir a la bola para escapar de la férula de suegras tiránicas; pero debemos tener cuidado antes de convertir a las suegras tiránicas en una causa genérica de revolución.

Una vez que traspasamos la narración individual y episódica, comenzamos a generalizar. ¿Cuáles son las generalizaciones que han surgido de la plétora de trabajos de estos últimos veinte años? Cuando, hace diez años, David Bailey escribió su resumen de la historiografía revolucionaria, percibió un revisionismo que "estimula y confunde", y que no tenía una dirección clara; "el único punto común", escribió, "es el reconocimiento de que hoy, hay menos acuerdo sobre el carácter y la significación de la Revolución", 4 que durante los cincuenta años transcurridos desde que los académicos le prestaron atención por primera vez. Bailey, entonces, entendió el revisionismo como una especie de antítesis embrionaria, un repudio negativo a lo viejo, sin constituir aún una alternativa positiva. No estoy seguro de que ahora esté consolidada esta alternativa positiva, o de que podamos hablar del revisionismo -ya no tan nuevo- consolidado en una ortodoxia (este punto es discutible). Pero sí podemos discernir rasgos interpretativos comunes dentro del cuerpo revisionista y, si bien el revisionismo todavia no compone la corriente principal (quizás no hay una corriente principal), representa una corriente poderosa, y no una mera multitud de remolinos sin orden ni concierto. Esta corriente incluye varios de los trabajos locales/regionales referidos, y como mínimo tres de las seis sintesis principales que mencioné (las de Meyer, Guerra y Ruiz). La corriente rival más fuerte -en el nivel de la gran síntesis- es la marxista, representada en general por trabajos bastante esquematizados y carentes de datos originales de archivo: por ejemplo, los libros de Anatol Shulgovski o Adolfo Gilly (el reciente Revolutionary Mexico de John Hart pertenece a este mismo campo teórico, pero incorpora un arsenal de datos de archivo, que apoyan primero las ideas tradicionales de una revolución popular agraria, con que coincido, segundo -y recalcada en el trabajo de Hart- de una revolución popular xenófoba, con que no coincido).

Pero es el punto de vista revisionista más que el marxista el que ha estado de moda últimamente. Hablaré del revisionismo, primero dentro del contexto de la revolución armada; es lo que mejor conozco y creo que tiene sentido analítico comenzar ahí. La esen-

\footnotetext{
4 David Bailey, "Revisionism and the Recent Historiography of the Mexican Revolution", Hispanic American Review, núm. 58, 1978, p. 63.
} 
cia de la interpretación revisionista es quitar énfasis y a veces negar al carácter popular y agrario de la Revolución; no resta importancia a un aspecto de la vieja ortodoxia que yo pondría en duda, es decir la supuesta honda xenofobia, que se alega subyace en la Revolución y que yo considero muy exagerada. Sin embargo -y este es el punto central- de acuerdo a la interpretación revisionista, el campesinado desempeñó un papel limitado y dependiente; la clase media y las elites terratenientes marcaron el paso. El zapatismo (cuyo carácter popular y agrario nadie puede negar) es la excepción que confirma la regla. En efecto, el tratamiento que un escritor le da al zapatismo proporciona a menudo una rápida prueba de tornasol del revisionismo: ¿es el zapatismo un ejemplo poderoso de un fenómeno más difundido (la vieja ortodoxia) o una aberración singular (el revisionismo)? Incidentalmente, esto quiere decir que trabajos superficiales que, al discutir la rebelión campesina, se limitan al caso zapatista, tienden a reforzar la idea -revisionista- de la peculiaridad del mismo. Mientras tanto, los análisis que se van al otro extremo y denotan movimientos muy divergentes - como el villismo, la Cristiada- como sencillamente "agraristas", también amparan al revisionismo, al ofrecerle blancos fáciles y baratos. Tales afirmaciones superficiales de un agrarismo omnipresente, frecuente entre escritores radicales y raras veces apoyadas por buenos datos, se parecen a las célebres guerras floridas del México de antes de la conquista; es decir, son tareas que tiran a fútiles, que no hacen sino proveer a los aztecas revisionistas de su cuota necesaria de víctimas para sacrificios (ofrece un ejemplo la síntesis de la historia agraria mexicana de John Tutino que, por otra parte excelente, muestra señas de descarrilarse cuando entra en la época revolucionaria). Y se pueden buscar otros sellos del revisionismo: el subrayar el papel de los terratenientes y de los caciques como líderes revolucionarios claves; el negar la significación de la revolución maderista (una mera llamarada de petate) y el esfuerzo elaborado para rehabilitar a Huerta (basado en el argumento de que, si la Revolución le confirió el papel del villano, entonces no puede ser tan malo; ésta es una de las formas más sencillas del revisionismo, puesto que se trata de una simple inversión de la vieja ortodoxia maniquea de la Revolución).

No puedo más que dar algunos ejemplos ilustrativos del enfoque revisionista. "La mayoria del campesinado mexicano (...) no estaba muy involucrado en la Revolución de 1910-20", escribe Hobsbawm, basándose en una lectura (quizás ligera) de Jean Meyer. Una lectura exagerada, sin duda, pero no del todo sorprendente, porque el mismo Meyer a veces da la impresión que -en términos de movilización popular- la Cristiada eclipsó a la Revolución. Y Jean Meyer, como su tocayo norteamericano, Michael C. Meyer, también tiene que defender a Huerta, ya que reconoce, a regañadientes, el consentimiento católico al golpe y al régimen huertista. El escape final es afirmar la amplia popularidad de Huerta: "Es verdad", dice Meyer, "que miembros eminentes del Partido Católico Nacional participaron en el gobierno de Huerta, pero, ¿quién no era partidario de Huerta?"' Por falta de espacio me abstengo de contestar.

${ }^{5}$ Jean Meyer, La révolution mexicaine, París, Calmann-Lévy, p. 11. 
En lo que concierne a los capitanes y controladores terratenientes de la Revolución, figuran en la obra de Falcón como elementos clave en un argumento dirigido específicamente tanto contra Tannenbaum (representante de la vieja ortodoxia) como contra Gilly (ejemplo del marxismo de hoy), pues Falcón comenta que ambos cometen el error de resaltar el papel autónomo de las fuerzas campesinas; ella, en contraste, subraya "la decisiva participación de las clases medias y sectores acomodados en la conducción de la revuelta (maderista)", estos grupos iniciaron la rebelión, que "encontró eco popular", y lograron mantener su hegemonía sobre sus adherentes populares tardíos en los años siguientes. ${ }^{6}$ Del mismo modo, Ramón Ruiz ve a los maderistas, no como campesinos sino como pequeños empresarios y otros deseosos de mejorar su posición social, padres de familia, rancheros, dueños de tierras que a menudo quedaban al cuidado de sus hijos. ${ }^{7}$ Esto suena bastante dudoso tanto desde una perspectiva generacional como desde una perspectiva socioeconómica: la revolución armada fue la obra de los jóvenes, no de los de mediana edad. Nótese, también, el énfasis en las aspiraciones crecientes y la movilidad ascendente, que caracteriza varios de los trabajos revisionistas (por ejemplo, el de Paul Vanderwood). Y no se trata solamente de la revolución maderista, pues las citas de Ruiz -y su modo de análisis generalacopla sucesivas olas de rebelión bajo una rúbrica similar. El liderazgo revolucionario -ya sea en 1910,1913 o 1915- se percibe como de clase media, si no alta: "de las lumbreras rebeldes", escribe, "sólo un manojo habia venido de los pueblos rurales", por otro lado, "tenderos y comerciantes, casi siempre de las ciudades de las provincias, participaron en la rebelión desde el comienzo"; asi lo hicieron también los terratenientes. Ruiz menciona alrededor de una docena, que incluye en su perfil de los rebeldes: varios de estos son, en realidad, oportunistas puros, cuyas credenciales "revolucionarias" se deben ya a adhesiones tardias dirigidas a proteger su propiedad, ya a propuestas serviles a un Carranza victorioso, escritas desde el exilio en Nueva York.

Claro que hubo algunos terratenientes revolucionarios. Algunos eran líderes pioneros de las fuerzas populares (a veces, serranos); como tales eran miembros legítimos del movimiento popular, compartiendo tón sus adherentes campesinos una antipatía común hacia la centralización y el "progreso" porfírianos. Su participación no niega el carácter popular de la Revolución. Algunos, por otra parte, eran liberales acérrimos a los outs (los fuera del poder) frustrados. Pero no tantos, y no suficientes para quitar a la Revolución su etiqueta popular. No proporcionaron la principal fuerza motriz del movimiento; al contrario, la mayoría de los terratenientes resistieron a la Revolución, fieles a Díaz hasta que su causa se vio perdida, después confiaron en De la Barra, Reyes, Huerta, herederos del manto porfiriano. En última instancia, algunos hacendados se convertían tardiamente a la Revolución por razones de

${ }^{6}$ Romana Falcón, "Los orígenes populares de la revolución de 1910. El caso de San Luis Potosi", Historia mexicana, núm. XXIX, México, El Colegio de México, p. 198-199.

${ }^{7}$ Ramón Eduardo Ruiz, The Great Rebellion. México 1905-1924, Nueva York, W. W. Norton \& Co., 1980, p. 214.

${ }^{8}$ Ibid., p. 216, 230, 234-235. 
necesidad, especialmente después de 1915, al comenzar su fase más conservadora y en 1920, cuando Obregón hizo pactos por doquier. En términos generales y nacionales, ninguno de estos grupos era lo suficientemente numeroso, poderoso, o, sobre todo, precoz, como para detener o controlar el movimiento popular armado. Además, dejando de lado a los pioneros serranos, los terratenientes hicieron su contribución histórica mayor precisamente en la contrarrevolución, especialmente en el sur, como han mostrado Alicia Hernández, Tom Benjamin y Javier Garciadiego. Hay que recalcar que, dados los cambios repentinos en el clima político de esta década, así como las grandes variaciones regionales de la Revolución, listas de "rebeldes terratenientes" que vienen de lugares y tiempos diversos y que a menudo responden a motivos distintos engañan mucho. Imagínense el caos conceptual que resultaria si se analizara igualmente la diversidad de la Revolución francesa, juntando a sus participantes "terratenientes", de modo que los primeros reformistas aristócratas se codearan con los rústicos bretones y los arribistas bonapartistas.

A la inversa, la participación y autonomía campesinas fueron mucho mayores de lo que los revisionistas -impresionados, quizás, por la aparente docilidad relativa del campesinado desde los años treinta, y la prevalencia de un caciquismo controlador- están preparados a admitir. No conozco ninguna forma de resolver este debate salvo intercambiando ejemplos, y no sé cómo cuantificar los ejemplos intercambiados. ¿Cuántos campesinos rebeldes se necesitan para que hablemos de una revolución campesina? ¿Cuántos terratenientes para que hablemos de una rebelión controlada por la elite? Tal vez nos puede ayudar John Coatsworth que ha demostrado gran habilidad para calibrar movimientos de protesta rural. Tengo que admitir que en mi propia investigación encontré muchos movimientos campesinos (lo que no significa, por supuesto, que todos tuvieran lideres cien por ciento campesinos) y otros investigadores parecen presentar más, hasta en regiones como Chihuahua, donde con frecuencia se ha considerado tenue el clásico sindrome campesino/agrario (me refiero a los trabajos de Alonso, Nugent y Koreck, sobre Namiquipa y Cuchillo Parado). Tales investigaciones refuerzan la noción de una revolución campesina popular en términos no sólo de número de cabezas campesinas contadas, sino también de los modos, las continuidades y el discurso de la protesta campesina. Es asi posible argumentar -en contraste con los que prefieren un modelo individualista de "actor racional" (por ejemplo Vanderwood)- que las comunidades campesinas revelaban ciertos valores compartidos distintivos, quizás arraigados en la "economia moral", que facilitaron su prolongada resistencia a las amenazas políticas y económicas. Tannenbaum no habló de la "economía moral", pero su noción de una revolución agraria, popular y defensiva se asimila fácilmente a este nuevo enfoque.

De la revolución en sí, podemos volver al Porfiriato. Si la Revolución no fue tanto una insurrección agraria, popular y amplia, sino más bien una serie de luchas de poder faccionales y controladas, resulta que la vieja leyenda negra también requiere revisión. $Y$ es el Porfiriato el objeto del trabajo más sitemático revisionista, el de F. X. Guerra. Es verdad que, antes de Guerra, Cosio Villegas ofre- 
ció una visión del antiguo régimen, cabal y calificada; mientras que Jean Meyer, escéptico acerca de la pretensión de la Revolución de representar a las masas oprimidas, también puso en duda el hecho de la opresión porfiriana: "el descontento popular por sí solo", escribió Meyer, "no hizo esta revolución. ¿Es que siquiera habia aumentado antes de 1910? No está para nada claro". Más que una revolución provocada por los crecientes agravios socioeconómicos, Meyer la percibe fomentada por la "modernización", por "el progreso rápido", "por la difusión de une prise de conscience a nivel de los sectores medios y altos de la sociedad", en breve, concluyó "es la revolución de las aspiraciones crecientes, favorecida por los sociológos norteamericanos". Mientras tanto, Meyer dice "para la mayoría de la gente, la vida siguió siendo severa, pero también palpablemente menos ruda, más fácil, y además más larga. No había guerra, ni hambre, ni peste".

Así, la Revolución ocurrió no tanto porque los pobres seguían empobreciéndose (o porque los pueblos seguían perdiendo sus tierras y su autonomía, que no es lo mismo que el simple empobrecimiento), sino porque la modernización generó nuevos grupos sociales, nuevas demandas, nuevas aspiraciones. Tenemos aquí, aplicada al México porfiriano, la sociologia norteamericana de Edward Shils, de mediados del siglo XX (hasta con su énfasis en los intelectuales declassés). Y mientras que Jean Meyer suscribe la tesis en términos bastante discursivos, hasta elipticos, Guerra ha presentado una obra masiva y de terminante certitud histórica. Los dos tomos de Guerra son voluminosos, detallados e impresionantes. Contienen un tesoro de valiosa información sobre el Porfiriato, la oposición y (más bien tardia y brevemente) los comienzos de la Revolución. Vale agregar que toda la información deriva de fuentes secundarias. A pesar de tal escasez de uso de archivos, Guerra ofrece varios argumentos estimulantes y convincentes: su reevaluación de los datos de censo es valiosa; su disección -al estilo del gran historiador Lewis Namier- de las elites y facciones porfirianas y del cursus honorum porfiriano merece elogios (le gana a Peter Smith en su propio territorio) y, su interpretación de la oposición política, sobre todo del maderismo, es una de las mejores que tenemos sobre ese fenómeno tan malentendido. Pero -a mi juicio- el análisis en su totalidad está uncido a una teoria tendenciosa y contraproducente. Por una parte, Guerra cree en la politica de facciones y en el clientelismo, que resulta bien pues facilita su perspicaz análisis de la política porfiriana. Por otra parte, cree en el poder de la ideologia "moderna", arraigada en el siglo de las luces, que según su perspectiva algo maniquea, está trabada en combate permanente con una serie rival de ideas, las de la "tradición". Lo que tenemos aquí son las viejas antítesis de la teoría de la modernización y de sus precursores (sagrado/secular, rural/urbano, gemeinschaft/gesellschaft), que se convirtieron en el ¡abrete sésamo! analitico para revelar los secretos de la historia de México desde los Borbones hasta los sonorenses. Lo que no tenemos -porque lo que Guerra omite es tan significativo como lo que incluye- es un análisis de clase. Los mexicanos de Guerra

9 Jean Meyer, La revolution..., op. cit., p., 23. 
estån organizados en facciones clientelistas, en movimientos ideológicos, o en comunidades homogéneas y holisticas (una palabra clave, aunque -para mí- un poco mistificadora). Los líderes sobresalientes son patrones o ideólogos. Movimientos campesinos autónomos, dotados de sentimientos de clase, no caben dentro del esquema. Además, su preocupación de lo político, heredado de la historiografía francesa, le hace pasar por alto un elemento de la ideologia "modernizadora" que deberia ser central en todo trabajo de este tipo: me refiero -por falta de una palabra mejor- al "desarrollismo" que impregnaba el pensamiento liberal, porfiriano y revolucionario, y que recalcaba la necesidad de educar, de moralizar, y -tanto literal como metafóricamente- de limpiar al pueblo mexicano sucio y degenerado. Este es un tema que Moisés González Navarro observó en su pionero El Porfiriato. La vida social y que otros especialistas -como Mary Kay Vaughan, JeanPierre Bastian, y William Beezley - han comenzado a explorar, y que yo creo merece recibir más atención, sobre todo por los aficionados al análisis del discurso y de la ideologia.

De este modo, el esquema de Guerra es algo restrictivo y tradicional (es conservador en más de un sentido); a pesar de su osado revisionismo, opera dentro de un contexto familiar dado y esencialmente político, dentro del cual elige dar la vuelta a suposiciones corrientes (desconfia de la modernización, glorifica la tradición). También es un esquema global: para Guerra, el Tercer Mundo es (o era) una especie de Arcadia, de comunidades independientes, rústicas, holisticas, hasta "tribales", aferradas a creencias y costumbres tradicionales. En todo esto, "tradición" y "modernidad" suministran los conceptos clave, si bien se las da por sentado y nunca quedan adecuadamente aclaradas. Entonces, una pandilla de reformistas, intelectuales y liberales entrometidos entra en la Arcadia. Para México, el proceso de degeneración comienza con los Borbones (arquitectos de un Estado centralizador y anticlerical: Jean Meyer, por supuesto, tampoco estima a los Borbones; igual que ese otro decano de la escuela procatólica o antianticlerical. mi compatriota y amigo David Brading). La degeneración se acelera durante el siglo XIX cuando los francmasones adquieren un papel ubicuamente subversivo; el régimen de Díaz representa una especie de aplazamiento o amortiguamiento del antiguo conflicto entre modernizadores y tradicionalistas, con el presidente desempeñando un papel benévolo y paternalista, protegiendo -al estilo de los Habsburgo- a las comunidades tradicionales amenazadas (los campesinos, se nos dice, consideraban a Diaz como habian considerado a los reyes de España). Por desgracia, con la Revolución las elites modernizadoras (más intelectuales deracinés, liberales, francmasones, todos armados con una filosofía dogmática, universal e individualista, algunos hasta manchados por el protestantismo) entran al poder. Estos reformistas y arquitectos del Estado arribista hacen ahora trizas a la tradición, a la comunidad, y a la hacienda (según Guerra, la hacienda, otra institución holistica, retiene un carácter decididamente benévolo y legítimo). El libro de Guerra se termina en 1911; quizás su ordenador estaba ya saturado; quizás su dueño no podia contemplar el apocalipsis final del México viejo, católico y tradicional, y el triunfo del liberalismo secular y centralizador. 
Aunque el esquema de Guerra es global, también es -como tanta teoría de la modernización- muy eurocéntrico. México es una extensión de la Europa romana y medieval. Cicerón y la villa merovingia ofrecen modelos que México ha seguido fielmente; México es una "prolongación" de Europa. España provee el modelo de una sociedad tradicional establecida sobre el pactismo (le pactisme); el presunto descenso de gastos ceremoniales en los pueblos indígenas del siglo XViII queda demostrado por analogía con Sevilla; la importancia omnipresente de la francmasonería en la política de México en el siglo XIX se sostiene con el argumento original de que el $39 \%$ de los delegados al Congreso Constituyente Español de 1931 fueron masones Q.E.D.

Pero el modelo clave es Francia. Repetidamente Guerra cita el estudio de Augustin Cochin sobre las sociedades librepensadoras francesas del siglo XVIII, que Cochin vio como los solventes del antiguo régimen. Guerra traslada la tesis de Cochin y la aplica, sistemáticamente, a México. Intenta desempeñar, para el Porfiriato y la Revolución, el mismo papel historiográfico contrarrevolucionario que Cochin y sus seguidores recientes (notablemente Francois Furet) han tratado de desempeñar en el caso francés: es decir, derrocar la vieja interpretación clasista (o, como se la llama, la "interpretación social"), la de Lefebvre, Soboul y otros, y sustituirla con otra que subraya el papel central de las elites intelectuales -librepensadores, francmasones liberales reformistas- que imponen su proyecto elitista y secularizador sobre una sociedad tradicional y hostil). Asi, la Revolución se concibe como un hecho político más que social; un hecho carente de significación en términos de clase (por lo tanto, no puede ser considerada una revolución burguesa); pero un hecho que acarrea la subversión de la tradición en favor de la modernidad, la sustitución de los viejos lazos y lealtades holísticos por nuevos lazos ideológicos, cerebrales y atómicos.

No es una coincidencia que Guerra cuente bastante con Francisco Bulnes para sus apuntes mexicanos, así como cuenta con Cochin (además de Pierre Chaunu, Roland Mousnier y Louis Dumont) para su enfoque teórico. Bulnes, el conservador porfiriano inconforme, es el predilecto del revisionismo: tanto Ramón Ruiz como Jean Meyer confían bastante (yo diría demasiado) en su autoridad discutible. Así, los lamentos de la derrocada elite porfiriana, sus diatribas contra los arribistas, entrometidos y oportunistas revolucionarios, forman parte del esquema de Guerra y armonizan con los estribillos propios de Cochin, que a su vez reflejaban su posición como miembro de una familia conservadora y aristocrática, empapada, como dice Furet, "en el tradicionalismo católico y la hostilidad hacia el régimen republicano."

En una palabra, Guerra combina un montón de datos, sacados de fuentes secundarias, con una metodología de alta tecnologia, para imponer sobre el México porfiriano y revolucionario un esquema eurocéntrico -y aún más, francocéntrico- que concibe la Revolución como el triunfo político supremo de las elites modernizadoras, enemigas de la tradición, del catolicismo, y de las comunidades contentas y holisticas del viejo México. Condena a la Revolución (como hizo Cochin), embellece el antiguo régimen y descarta el concepto de clase. Uno puede decir que la Revolu- 
ción fue todo eso y hasta cierto punto sí lo fue. Pero se necesita equilibrio. Una teoría de la modernización vulgar no supera un marxismo vulgar. El pleito principal contra Guerra debe ser que su interpretación es polémica y parcial, que impone categorias estrechamente políticas, francocéntricas y carentes de sentido de clase, sobre lo que fue una revolución social, mexicana (por supuesto) y cargada de conflictos de clase, sobre todo en los años 1910-1915.

También lleva a un concepto erróneo en lo que concierne al resultado de la Revolución; y así a su carácter fundamental. El análisis de Guerra, aunque se termina en 1911, cuadra con la corriente principal revisionista que subraya tanto la naturaleza politica y elitista de la Revolución, como las continuidades que la vinculan al pasado, dándole un carácter más bien "neoporfiriano" que verdaderamente revolucionario. Para Guerra y otros, sugiere Vanderwood, "la Revolución es considerada meramente otro blip, aunque un blip bastante grande (...) en la historia de México". Ramón Ruiz se esfuerza en señalar que la Revolución no fue una verdadera revolución, sino una "gran rebelión", o un mero "motín”. Según Ruiz, la Revolución "modernizó" algo el capitalismo, pero de ninguna manera transformó la sociedad. Sus efectos principales fueron políticos (aqui se invoca ritualmente a Tocqueville); propició la circulación de algunas elites y la creación de un Estado poderoso y centralizado; esencialmente llevó a cabo la obra de los Borbones, de los liberales del siglo XIX y del mismo Porfirio Diaz. Asi, los estudios revisionistas del periodo posrevolucionario se concentran en el desarrollo del Estado (en otra parte me he referido a este enfoque como "estadolatría", un Estado que se constituye por encima de la sociedad, "relativamente autónomo", hasta bonapartista (otra interpolación francesa); en fin, un Estado que mezcla y soba la masa inerte de la sociedad civil más o menos a su antojo. ${ }^{10}$ Este enfoque no sólo encaja muy justamente con el revisionismo de la Revolución francesa, sino que también se inspira en algunas teorias recientes de revolución, como la de Theda Skocpol, que agrupa las revoluciones "burguesas" y "socialistas" bajo una rúbrica común, calificándolas igualmente de fenómenos conducentes al fortalecimiento del Estado, muy determinados por actores estatales y por el ambiente internacional, y así relativamente independientes de las fuerzas sociales domésticas.

Por falta de tiempo, y porque he tratado este tema en otro artículo, no analizo la interpretación revisionista del México posrevolucionario de una manera detallada. Pero hay tres objeciones básicas. Primero, hay objeciones teóricas contra tales Estados relativamente autónomos. No encajan cómodamente dentro de las teorias marxistas y liberal-pluralistas. A veces, el Estado relativamente autónomo o bonapartista aparece como un Deus ex $\mathrm{Ma}$ china: se recurre a él cuando todos los otros factores explicativos fracasan, o parecen fracasar. Es también un primer motor, algo que afecta pero a su vez no es afectado. En segundo lugar, empiricamente es discutible. El poder del Estado mexicano en la época 1910-40 era, a mi juicio, mucho menos de lo que se imagina (otra

${ }^{10}$ Alan Knight, "The Mexican Revolution: Bourgeois? Nationalist? Or Just a 'Great Rebellion'?', Bulletin of Latin American Research, núm. 4, p. 1-37. 
vez, no hay criterios establecidos para medir el poder del Estado; quizás en los próximos veinte años los historiadores puedan trabajar sobre esta cuestión). Por otra parte, el poder y la autonomía de la sociedad civil eran mayores. La sociedad civil puede haberse encontrado en turbulencia y confusión, pero no era una sociedad carente de clases, asociaciones y grupos organizados. Repetidamente, el Estado fue abofeteado por conflictos que surgieron de la sociedad, y los esfuerzos del Estado de restringir o canalizar estos conflictos fallaron. En décadas sucesivas tanto el callismo como el cardenismo brotaron, florecieron y se marchitaron. La batalla contra la Iglesia en los años veinte terminó en tablas; la campaña en pro de la educación socialista en los treinta fracasó. Esto no es la carrera de un gran Leviatán.

Además, los cambios que se produjeron en la sociedad civil desde 1910 fueron profundos y dignos de la etiqueta de "revolucionarios". No porque las nuevas elites revolucionarias siempre los propiciaron (muchas veces no lo hicieron). La reforma agraria oficial -el ejemplo clave- avanzó lentamente, a veces a regañadientes. Por eso, algunos historiadores sugieren que los años veinte fueron básicamente "neoporfirianos" en términos de la continuación no sólo del desarrollo capitalista sino también de la hegemonia de la hacienda (quizás hay una contradicción aqui). En mi opinión, el desarrollo capitalista fue profundamente afectado por el cambio agrario, un cambio que a menudo no resultó de la política oficial, sino de la presión popular y local: primero, con la revolución armada, después con el largo y penoso proceso de la lucha agrarista. Este no fue un proceso iniciado y siempre controlado por el Estado; tampoco fue un proceso superficial. Mucho antes de que Cárdenas acelerara la distribución de tierras, la hacienda estuvo sujeta a una presión dura, a veces debilitante, y la clase terrateniente fue perdiendo la hegemonía política y social que habia disfrutado durante el Porfiriato.

Esto era algo que Tannenbaum y otros -observadores de primera mano- apreciaban muy bien; es algo que a los historiadores de hoy, distanciados de ese tiempo, a veces aficionados a la certeza estadística (otra contradicción) y familiarizados con el campesinado minoritario y más dócil de hoy, les cuesta trabajo concebir en general. Por lo tanto, muchos dan énfasis al carácter elitista, cínico y desde el agrarismo; ven al ejido como un sistema ajeno, impuesto a comunidades felices y bucólicas; es otra imposición de elites reformistas - borbónicas, liberales, revolucionarias- que buscan la modernización de una población rural, tradicional, contenta y conservadora. La educación secular también se ve como una aplanadora que arrasa a un pueblo hasta ahora fiel y feliz. El conflicto viene a la sociedad rural desde afuera y desde arriba, no desde adentro; y es un conflicto político más que social. Otra vez, el revisionismo subraya el papel de las elites (que, por supuesto, está mejor documentado), subestima la movilización popular y tiende a pasar por alto los cambios básicos con respecto a la mentalidad y la organización populares. Empero, tales cambios, indicativos de una transformación real en el clima político y social, son características de la Revolución -de cualquier revolución auténtica- aunque no sean cuantificables y no salten de las páginas de muchas fuentes secundarias. 
También es bien probable que tales cambios sean violentos, caóticos y en absoluto gratos. Relaciones de propiedad y de clase no se cambian según acuerdos pulcros y consensuales. De ahí, el proceso revolucionario, especialmente el proceso agrarista, está lleno de relatos de conflicto, violencia, resistencia y faccionalismo. No obstante ciertas versiones, esto no quiere decir que el agrarismo fuera un mero medio de control elitista, faccionista, ni que los campesinos fueran meras marionetas manipuladas, ni que el ejido fuera una sencilla imposición ajena. Como Paul Friedrich ha mostrado bien, la política maquiavélica y el caciquismo, el agrarismo y la violencia, corren parejas y -podemos sugerir- hubiera sido extraño de no ser así. La destrucción del viejo régimen en el México rural apenas podía avanzar según la práctica de la democracia social europea. La cara fea del agrarismo fue inseparable de su cara progresista y transformadora, y no vale la pena moralizar acerca de esto. La revolución es la revolución, como dijo Cabrera; que quizás quiere decir que debemos aceptar la Revolución tal como fue, olvidar los juicios de valor, y tratar de contar lo que pasó, por qué. y con qué resultado. No debemos llorar la muerte de Arcadias perdidas (y quizás imaginarias).

Por último, el revisionismo tiende a homogeneizar la historia moderna de México, mientras que afirma la variedad geográfica infinita del país. Guerra comprime el largo siglo XIX dentro de su dicotomia preferida, de manera que los yorkinos del mil ochocientos veinte cohabitan con los magonistas de mil novecientos; ambos grupos son protagonistas de la modernidad. Los estadolatristas vinculan la historia posrevolucionaria a la marcha inexorable del Estado. Coyunturas clave quedan descuidadas: 1910, cuando, ante la sorpresa general, el régimen de Diaz se derrumbó; 1915, cuando el triunfo carrancista aseguró que el Estado centralizador se consolidara otra vez, aunque con mucha dificultad; 1934-35, cuando un nuevo proyecto radical irrumpió en la escena política (impulsado, en parte, por la presión popular) y, por último, 19381940 , cuando este proyecto vaciló, sus enemigos se reanimaron y la marea comenzó a cambiar en favor de otro proyecto, que todavía queda en vigor, si bien bastante debilitado, quizás moribundo.

Para concluir, hoy sabemos mucho más acerca de la Revolución que hace veinte años; nuestras fuentes y metodologias se han diversificado: nuestro conocimiento de las variaciones regionales de la Revolución ha crecido notablemente y, con ello (aunque en menor grado), nuestra comprensión de unos temas importantes: caudillos y caciques, campesinos y obreros. Pero nuestro entender de la Revolución en su totalidad no ha mejorado en proporción. Estudios de caso no se integran fácilmente en sintesis globales; pueden estorbar tales sintesis. También las sintesis necesitan bases teóricas $\mathrm{y}$, a veces, éstas han sido insuficientes y hasta contraproducentes. Y buena parte del revisionismo ha sido revisionismo por revisionismo, inversiones simples de la vieja ortodoxia o refutaciones atrevidas de una ortodoxia caricaturizada. Según mi juicio, la ortodoxia, la obra de participantes y observadores penetrantes, todavía tiene mucha validez. Por supuesto, muestra defectos: exagera el contenido xenófobo de la Revolución y muchas veces denomina "indios" a los que otros llamarían campesinos. Pero su visión básica de una revolución agraria y popular, que 
derrocó a un antiguo régimen carente de legitimidad y que fomentó unos cambios decisivos en la sociedad mexicana (cambios que tal vez constituyen elementos de una revolución burguesa), sigue siendo válida. Merece modificaciones consideradas más que rechazos rotundos. Como nosotros, los de la tercera generación, miramos hacia atrás a los que nos precedieron, les debemos quizás un poco más del respeto confuciano y un poco menos del resentimiento edípico.

\section{Bibliografía}

Aguilar Camin, Héctor, La frontera nómada: Sonora y la Revolución mexicana, México, Siglo Xx1, 1977.

Alvarado, Salvador, La reconstrucción de México: Un mensaje a los pueblos de América, México, J. Ballescá y Cía., 1919.

Amerlinck de Bontempo, Marijosé, "La reforma agraria en la hacienda de San Diego de Rio Verde", en García Moreno, Después de los latifundios 1982, p. 183-198.

Anderson, Rodney, Outcasts in Their Own Land. Mexican Industrial Workers, 1906-1911, DeKalb, Northern Illinois University Press, 1976.

Ankerson, Dudley, Agrarian Warlord. Saturnino Cedillo and the Mexican Revolution in San Luis Potosi, DeKalb, Northern Illinois University Press, 1984.

Archivo de la Palabra, Instituto de Investigaciones Dr. José María Luis Mora, México.

Ashby, Joe C., Organized Labor and the Mexican Revolution Under Lazaro Cardenas, Chapel Hill, University of North Carolina Press, 1963.

Bailey, David C., Viva Cristo Rey! The Cristero Rebellion and Church-State Conflict in Mexico, Austin, University of Texas Press, 1974.

Bailey, David C., "Revisionism and the Recent Historiography of the Mexican Revolution", Hispanic American Historical Review, num. 58, 1978, p. 62-79.

Becker, Marjorie, "Lázaro Cárdenas, Cultural Cartographers, and the Limits of Everyday Resistance in Michoacan, 1934-1940", ponencia presentada en el 46th International Congress of Americanists, Amsterdam, 1988.

Beezley, William H., Insurgent Governor: Abraham Gonzalez and the Mexican Revolution in Chihuahua, Lincoln, University of Nebraska Press, 1973.

Beezley, William, Judas at the Jockey Club and Other Episodes of Porfirian Mexico, Lincoln, University of Nebraska Press, 1987.

Bellingeri, Marco, "L'economia del latifondo in Messico. L'hacienda San Antonio Tochtlaco dal 1880 al 1920", Annali della Fondazione Luigi Einaudi, núm. X, 1976 , p. $287-428$.

Benjamin, Thomas L., Passages to Leviathan: Chiapas and the Mexican State, 1891-1947; tesis de doctorado, Michigan State University, 1981.

Benjamin, Thomas L. y William McNellie, eds., Other Mexicos: Essays on Mexican Regional History, 1876-1911, Albuquerque, University of New Mexico Press, 1984.

Blanco Moheno, Roberto, Crónica de la Revolución mexicana de la decena trágica a los campos de Celaya, México, Libro Mexicano, 1961 (3 vols.).

Brading, D. A., Caudillo and Peasant in the Mexican Revolution, Cambridge, Cambridge University Press, 1980.

Britton, John A., Educación y radicalismo en México, México, SEP, 1976 (Sepsetentas).

Bulnes, Francisco, El verdadero Diaz y la Revolucion, México, Editora Nacional, 1967.

Buve, Raymond, "Peasant Movements, Caudillos and Land Reform during the Revolution (1910-17) in Tlaxcala, México", Boletín de Estudios Latinoamericanos y del Caribe, núm. XVIII, 1975, p. 112-152.

Carr, Barry, El movimiento obrero y la polítia en México, México, SEP, 1976 (Sepsetentas).

Clendenen, Clarence C., The United States and PanchoVilla: A Study in Unconventional Diplomacy, Ithaca, Cornell University Press, 1961.

Coatsworth, John H., El impacto ecónomico de los ferrocarriles en el Porfiriato, México, SEP, 1976 (Sepsetentas).

Córdoba, Arnaldo, La ideología de la Revolución mexicana: La formación del nuevo régimen. México, Ediciones Era, 1972. 
Cosio Villegas, Daniel, Historia Moderna de México, 1955-65, México, Editorial Hermes.

Craig, Ann L., The First Agraristas. An Oral History of a Mexican Agrarian Reform Movement, Berkeley y Los Angeles, University of California Press, 1983.

Cumberland, Charles C., The Mexican Revolution: Genesis Under Madero, Austin, University of Texas Press, 1952.

Cumberland, Charles C., The Mexican Revolution: The Constitutionalist Years, Austin, University of Texas Press, 1972.

Fabela, Isidro, Historia diplómatica de la revolución constitucionalista, México, Fondo de Cultura Económica, 1959.

Falcón, Romana, El agrarismo en Veracruz. La etapa radical (1928-1935), México, El Colegio de México, 1977.

Falcón, Romana, "Los orígenes populares de la Revolución de 1910. El caso de San Luis Potosi", en Historia mexicana. XXIX, 1979, México, El Colegio de México, p. 197-240.

Falcón, Romana, Revolución y caciquismo: San Luis Potosi, 1910-1938, México, El Colegio de México, 1984.

Falcón, Romana y Soledad García, La semilla en el surco: Adalberto Tejada y el radicalismo en Veracruz (1883-1960), México, El Colegio de México, 1986.

Fowler Salamini, Heather, Agrarian Radicalism in Veracruz 1920-1937, Lincoln, University of Nebraska Press, 1971.

Friedrich, Paul, Agrarian Revolt in a Mexican Village, Englewood Cliffs, PrenticeHall, 1970.

Friedrich, Paul, The Princes of Naranja: An Essay in Anthropohistorical Method, Austin, University of Texas Press, 1986.

Furet, Francois, Interpreting the French Revolution (trad. Elborg de Foster), Cambridge, Cambridge University Press, 1981.

Garcia Díaz, Bernardo, Un pueblo fabril del Porfiriato: Santa Rosa, Veracruz, México, Fondo de Cultura Económica, 1981.

Garciadiego Dantan, Javier, "Revolución constitucionalista y contrarrevolución (Movimientos reaccionarios en México, 1914-1920)", tesis de doctorado, El Colegio de México, 1981.

Gavira, Gabriel, General de brigada Gabriel Gavira: Su actuación político-militar revolucionaria, México, Talleres Gráficos de A. del Bosque, 1933.

Gilly, Adolfo, La revolución interrumpida: México 1910-1920, una guerra campesina por la tierra y el poder, México, Ediciones El Caballito, 1971.

González, Luis, Pueblo en vilo: Microhistoria de San José de Gracia, México, El Colegio de México, 1972.

González, Luis, coord., Historia de la Revolución mexicana, México, El Colegio de México.

González Casanova, Pablo, coord., La clase obrera en la historia de México, Mexico, Siglo XXI.

Gruening, Ernest, Mexico and its Heritage, Londres, Stanley Paul \& Co., 1928.

Guerra, François-Xavier, Le Mexique de l'Ancien Régime à la Révolution, París, L'Harmattan, 1985.

Hall, Linda, Alvaro Obregón: Power and Revolution in Mexico, 1911-1920, College Station, Texas A \& M University Press, 1981.

Hart, John Mason, Anarchism and the Mexican Working Class, 1860-1931, Austin, University of Texas Press, 1978.

Hart, John Mason, Revolutionary Mexico. The Coming and Process of the Mexican Revolution. Berkeley. University of California Press, 1987.

Hernández Chávez, Alicia, "Militares y negocios en la Revolución mexicana", Historia Mexicana, op. cit., 34, 1984, p. 181-212.

Hobsbawm, Eric J., "Peasants and politics", Journal of Peasant Studies, I, 1973, p. $1-22$.

Jacobs, Ian, Ranchero Revolt: The Mexican Revolution in the State of Guerrero, Austin, University of Texas Press, 1982.

Jornadas de historia de occidente: Movimientos populares en el occidente de México, siglos $X I X$ y $X X$, Jiquilpan, Centro de Estudios de la Revolución Mexicana "Lázaro Cárdenas", 1981.

Joseph, Gilbert, Revolution From Without: Yucatan, Mexico and the United States, 1880-1924, Cambridge, Cambridge University Press, 1982.

Katz, Friedrich, The Secret War in Mexico: Europe, the United States and the Mexican Revolution. Chicago, University of Chicago Press, 1981.

Katz, Friedrich, ed., Riot, Rebellion and Revolution: Rural Social Conflict in Mexico. Princeton, Princeton University Press, 1987. 
Knight, Alan, "The Mexican Revolution: Bourgeois? Nationalist? Or Just a "Great Rebellion'?", Bulletin of Latin American Research, núm. 4, 1985, p. 1-37.

Knight, Alan, The Mexican Revolution. Cambridge, Cambridge University Press, 1986.

Knight, Alan, "Mexican Peonage: What Was It and Why Was It?", Journal of Latin American Studies, núm. 18, 1986, p. 41-74.

Knight, Alan, "Thoughts on the Demise of the Hacienda, 1910-1940", ponencia presentada en la 46th International Congress of Americanists, Amsterdam, 1988.

Koreck, Maria Teresa, "Space and Revolution on Chihuahua's Eastern Border", en Nugent y Alonso, eds., Rural Revolt. The Mexican State and the U.S., San Diego, Center for the US-Mexican Studies, 1988.

Krauze, Enrique, La biografia del poder, México, Fondo de Cultura Económica, 1987.

Leal, Juan Felipe y Mario Huacuja, Fuentes para el estudio de la hacienda en México, 1856-1940, México, UNAM, 1977.

Lerner, Victoria, Historia de la Revolución mexicana. La educación socialista, México, El Colegio de México, 1979.

Lieuwen, Edwin, Mexican Militarism: the Political Rise and Fall of the Revolutionary Army, 1910-1940. Albuquerque, University of New Mexico Press, 1968.

Martínez Assad, Carlos, El laboratorio de la Revolución: El Tabasco garridista, México, Siglo Xxı, 1979.

Martínez Assad, Carlos, ed., La Revolución en las regiones, Guadalajara, Universidad de Guadalajara, 1986.

Martínez Assad, Carlos, ed., Estadistas, caciques y caudillos, México, Instituto de Investigaciones Sociales, UNAM, 1988.

Meyer, Jean, La révolution mexicaine, Paris, Calmann-Lévy, 1973.

Meyer, Jean, La Cristiada, México, Siglo XXI, 1974.

Meyer, Michael C., Mexican Rebel: Pascual Orozco and the Mexican Revolution, Lincoln, University of Nebraska Press, 1967.

Meyer, Michael C., Huerta: A Political Portrait, Lincoln, University of Nebraska Press, 1972.

Miller, Simon, "The Nineteenth-Century Arable Hacienda as an Efficient Economic Adaptation", ponencia presentada en la 46th International Congress of Americanists, Amsterdam, 1988.

Molina Enríquez, Andrés, Los grandes problemas nacionales, México, A. Carranza, 1909.

Moreno García, Heriberto, ed., Despues de los latifundios (La desintegración de la gran propiedad agraria en México), Zamora, El Colegio de Michoacán, 1982.

Nickel; Herbert J., Soziale Morphologie der Mexikanischen Hacienda, Wiesbaden, Franz Steiner Verlag, 1978.

Nugent, Daniel y Ana María Alonso, eds., Rural Revolt. The Mexican State and the U.S., San Diego, Center for US-Mexican Studies, 1988.

Olivera Sedano, Alicia, Aspectos del conflicto religioso de 1926 a 1929. México, Instituto Nacional de Antropologia e Historia, 1966.

Paoli, Francisco y Enrique Montalvo, El socialismo olvidado de Yucatd́n, México, Siglo XXI, 1977.

Plana, Manuel, II Regno del Cotone in Messico: La Struttura Agraria de La Laguna, 1855-1910, Milán, Franco Angeli, 1984.

Quirk, Robert E., The Mexican Revolution: The Convention of Aguascalientes, Nueva York, 1960.

Raby, David L., Educación y revolución social en México, México, SEP, 1974 (Sepsetentas).

Richmond, Douglas, Venustiano Carranza's Nationalist Struggle, 1893-1920, Lincoln, University of Nebraska Press, 1983.

Ronfeldt, David, Atencingo: The Politics of Agrarian Struggle in a Mexican Ejido, Stanford, Stanford University Press, 1973.

Rojas, Beatriz, La destrucción de la hacienda en Aguascalientes, Zamora, El Colegio de Michoacan, 1981.

Ross, Stanley R., Francisco I. Madero: Apostle of Mexican Democracy, Nueva York, Columbia University Press, 1955.

Ruiz, Ramón Eduardo, Labor and the Ambivalent Revolutionaries: Mexico, 19111923, Baltimore, John Hopkins University Press, 1976.

Ruiz, Ramón Eduardo, The Great Rebellion. Mexico 1905-1924, Nueva York, W. W. Norton \& Co., 1980.

Ruiz, Ramón Eduardo. The People of Sonora and Yankee Capitalists, Tucson, University of Arizona Press, 1988. 
Ruiz Cervantes, Francisco José, La Revolución en Oaxaca. El movimiento de la soberania (1915-1920), México, Fondo de Cultura Económica, 1986.

Rutherford, John, Mexican Society During the Revolution: A Literary Approach, Oxford, Oxford University Press, 1971.

Schryer, Franz J., The Rancheros of Pisaflores. The History of a Peasant Bourgeoisie in Twentieth-Century Mexico, Toronto, University of Toronto Press, 1980.

Shulgovski, Anatol, México en la encrucijada de su historia, México, Cultura Popular, 1972.

Silva Herzog, Jesús, Breve historia de la Revolución mexicana, México, Fondo de Cultura Económica, 1960.

Skocpol, Theda, States and Social Revolutions: A Comparative Analysis of France, Russia and China, Cambridge, Cambridge University Press, 1980.

Smith, Peter H., Labyrinths of Power: Political Recruitment in Twentieth-Century Mexico, Princeton, Princeton University Press, 1979.

Tannenbaum, Frank, The Mexican Agrarian Revolution, Nueva York, The MacMillan Company, 1929.

Tannenbaum, Frank, Peace by Revolution: Mexico After 1910, Nueva York, Columbia University Press, 1966.

Tobler, Hans Werner, Die mexikanische Revolution: Gesellschaftlicher Wandel und politischer Umbruch, I876-1940, Frankfort, Suhrkamp Verlag, 1984.

Tutino, John, From Insurrection to Revolution in Mexico: Social Bases of Agrarian Violence, 1750-1940. Princeton, Princeton University Press, 1986.

Ulloa, Berta, La revolución intervenida. Relaciones diplomáticas entre México y Estados Unidos, México, El Colegio de México, 1971.

Valadés, José C., Historia general de la Revolución mexicana, Mexico, Editores Mexicanos Unidos, 1976.

Vanderwood, Paul, Disorder and Progress. Bandits, Police and Mexican Development, Lincoln, University of Nebraska Press, 1981.

Vanderwood, Paul, "Building Blocks but Yet No Building: Regional History and the Mexican Revolution", Mexican Studies/Estudios Mexicanos, núm. 3, p. $421-432$.

Vanderwood, Paul, "Explaining the Mexican Revolution", ponencia presentada en el Sixth Annual Mexico/Chicano Symposium, University of California, Irvine, abril, 1988.

Vargas Lobsinger, Maria, La Hacienda de "La Concha": Una empresa algodonera de La Laguna, 1883-1917, Mexico, UNAM, 1984.

Vaughan, Mary K., State, Education and Social Class in Mexico, 1880-1928, De Kalb, University of Northern Illinois Press, 1982.

Vázquez de Knauth, Josefina, Nacionalismo y educación en México, México, El Colegio de México, 1970.

Vera Estañol, Jorge, La Revolución mexicana: origenes y resultados, México, Editorial Porrúa, 1957.

Voss, Stuart F., On the Periphery of Nineteenth-Century Mexico: Sonora and Sinaloa, 1810-1877, Tucson, University of Arizona Press, 1982.

Warman, Arturo, ... Y venimos a contradecir. Los campesinos de Morelos y el Estado nacional, México, Ediciones de la Casa Chata, 1976.

Wasserman, Mark, Capitalists, Caciques, and Revolution: The Native Elite and Foreign Enterprise in Chihuahua, Mexico, 1845-19I1, Chapel Hill, University of North Carolina Press, 1984.

Wells, Allen, Yucatan's Gilded Age: Haciendas, Henequen and International Harvester, 1860-1915, Albuquerque, University of New Mexico Press, 1985.

Wilkie, James W., The Mexican Revolution: Federal Expenditure and Social Change since 1910, Berkeley, University of California Press, 1967.

Wilkie, James W. y Edna Monzón de Wilkie, México visto en el siglo $x x$. Entrevistas de historia oral, México; Instituto de Investigaciones Económicas, 1969.

Womack Jr. John, Zapata and the Mexican Revolution, Nueva York, Vintage Books, 1969.

Zevada, Ricardo J., Calles, el presidente, México, Editorial Nuestro Tiempo, 1971. 